\title{
Correction to: Using Business Process Compliance Approaches for Compliance Management with Regard to Digitization: Evidence from a Systematic Literature Review
}

Stefan Sackmann, Stephan Kuehnel, and Tobias Seyffarth

\section{Correction to:}

Chapter "Using Business Process Compliance Approaches for Compliance Management with Regard to Digitization: Evidence from a Systematic Literature Review" in: M. Weske et al. (Eds.): Business Process Management, LNCS 11080, https://doi.org/10.1007/978-3-319-98648-7_24

In the originally published version of chapter 24 , the total values of table 2 and the text on page 417 were initially published with errors. This has been corrected and the supplementary material has been updated. 